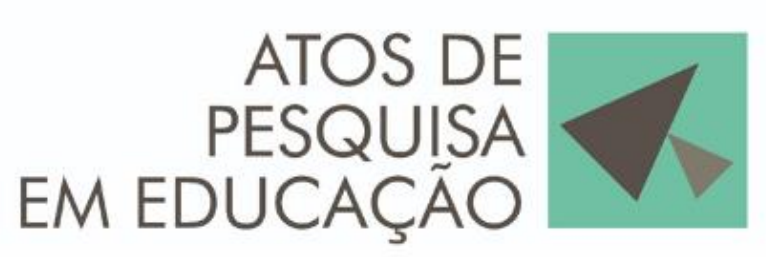

ISSN: 1809-0354

\title{
A ANÁLISE TEMÁTICA COMO METODOLOGIA NA PESQUISA QUALITATIVA EM EDUCAÇÃO EM CIÊNCIAS
}

\section{THEMATIC ANALYSIS AS A METHODOLOGY IN QUALITATIVE RESEARCH IN SCIENCE EDUCATION}

\section{EL ANÁLISIS TEMÁTICO COMO METODOLOGÍA EN LA INVESTIGACIÓN CUALITATIVA EN EDUCACIÓN EN CIENCIAS}

\author{
ROSA, Liane Serra da \\ lianeserra@bol.com.br \\ CAIC/FURG - Centro de Atenção Integral à Criança e ao Adolescente \\ https://orcid.org/0000-0003-4806-0857 \\ MACKEDANZ, Luiz Fernando \\ luismackedanz@furg.br \\ IMEF/PPGEC/FURG - Instituto de Matemática, Estatística e Física/ Programa de \\ Pós-Graduação em Educação em Ciências/Universidade Federal do Rio Grande \\ https://orcid.org/0000-0002-0138-0119
}

RESUMO: Neste trabalho, apresentamos a análise temática como procedimento analítico alternativo na pesquisa qualitativa. Apresentamos uma discussão sobre as diferentes formas de análise, com foco nas análises de conteúdo e do discurso, para sinalizar as diferenças com a análise temática. A partir de uma aplicação na pesquisa em educação em ciências, mostramos que esta alternativa não predispõe nenhuma teoria subjacente, e por isso não inclui nenhum viés na pesquisa, desde a produção dos dados. Assim, tal metodologia de análise pode ser utilizada em pesquisas da área da educação e do ensino, sem vinculação necessária a uma determinada corrente teórica, e pode ser trabalhada para alcançar resultados gerais, podendo ser posteriormente, se assim desejado, avaliados sob diferentes referenciais teóricos. Isto apresenta uma novidade em relação às metodologias de análise disponíveis, considerando que estas estão fortemente associadas a um arcabouço teórico próprio. Por esse motivo, defendemos sua aplicação de forma mais ampla para as áreas da educação e do ensino, para além da área da psicologia e da saúde, onde a mesma já é trabalhada.

Palavras-chave: Análise de conteúdo. Dialética. Hermenêutica.

ABSTRACT: In this work, we present thematic analysis as an alternative analytical procedure in qualitative research. We present a discussion about the different forms of analysis, focusing on content analysis and discourse, to signal the differences with the thematic analysis. From an application in research in science education, we show that this alternative does not predispose any underlying theory, and therefore does not 


\section{ATOS DE

include any bias in the research, since the production of the data. Thus, such an analysis methodology can be used in research in the area of education and teaching, without a necessary link to a particular theoretical current, and can be worked on to achieve general results, and can be subsequently, if so desired, evaluated under different theoretical frameworks. This presents a novelty in relation to the analysis methodologies available, considering that they are strongly associated with their own theoretical framework. For this reason, we defend its application more broadly to the areas of education and teaching, beyond the area of psychology and health, where it is already worked.

Keywords: Content analysis. Dialectics. Hermeneutics.

RESUMEN: En este trabajo, presentamos el análisis temático como procedimiento analítico alternativo en la investigación cualitativa. Se presenta una discusión sobre las diferentes formas de análisis, con foco en los análisis de contenido y del discurso, para señalar las diferencias con el análisis temático. A partir de una aplicación en la investigación en educación en ciencias, mostramos que esta alternativa no predispone ninguna teoría subyacente, y por eso no incluye ningún sesgo en la investigación, desde la producción de los datos. Por lo tanto, dicha metodología de análisis se puede utilizar en la investigación en el área de la educación y la enseñanza, sin un vínculo necesario con una corriente teórica determinada, y se puede trabajar para lograr resultados generales, y se puede evaluar posteriormente, si así se desea, bajo diferentes marcos teóricos. Esto presenta una novedad en relación con las metodologías de análisis disponibles, considerando que están fuertemente asociadas con su propio marco teórico. Por ese motivo defendemos su aplicación de forma más amplia para las áreas de la educación y la enseñanza, más allá del área de la psicología y de la salud, donde la misma ya es trabajada.

Palabras clave: Análisis de contenido. Dialéctica. Hermenéutica.

\section{INTRODUÇÃO}

Uma questão em discussão no Brasil concentra-se na dicotomia ciências exatas/naturais e ciências humanas/sociais. Apesar de grandes progressos nos últimos 50 anos, deixando a 'física social' Comteana para trás e estudando metodologias de pesquisa específicas para as ciências humanas, ainda existe na Academia (em especial a brasileira) uma indisposição quanto à natureza da pesquisa. Ou seja, ainda convivemos num ambiente fortemente positivista, que associa pesquisa ao método científico Cartesiano e análise de dados ao tratamento estatístico.

Com isso, não deixamos de valorizar os métodos estatísticos para o tratamento de dados quantitativos, que estão relacionados a medições e a busca da observação de padrões matemáticos na Natureza. Porém, a pesquisa na área de Ciências 


\section{ATOS DE \\ PESQUISA \\ EM EDUCAÇÃO}

ISSN: 1809-0354

3

Humanas, comumente, não se caracteriza por padrões genéricos, mas sim pela investigação do processo envolvido. Assim, os dados obtidos são muito mais qualitativos, associados ao discurso falado ou ao texto escrito, e necessitam métodos de análise subjetivos.

Esta distinção, porém, deve ser considerada mais sob o ponto de vista epistemológico, entre a natureza das generalizações que os dois tipos de pesquisa proporcionam (STAKE, 1983). Isso está em muito associado ao passo inicial da pesquisa: enquanto o procedimento quantitativo busca variáveis que descrevam a população para analisar, o procedimento qualitativo está focado em eventos ou casos que sejam de interesse para esta população.

No caso da Educação/Ensino em Ciências, isto fica muito claro, uma vez que os fenômenos estudados pouco conseguem uma caracterização completa a partir de variáveis e quantidades mensuráveis. Segundo Minayo (2008), ao tratarmos de pesquisa na área de Ciências Sociais e/ou Humanas, existem cinco pontos que tornam sua pesquisa peculiar: o objeto de estudo é histórico (existe num determinado espaço e tempo); os indivíduos estudados têm consciência histórica, em decorrência disso; o trabalho ocorre no nível da identidade entre sujeito e objetivo da investigação; é intrínseca e extrinsecamente ideológica, pois "na construção do conhecimento veiculam-se interesses e visões de mundo historicamente construídos" (MINAYO, 2008, p. 41-2); e por fim, o objeto de estudo é essencialmente qualitativo, uma vez que busca os significados constituídos a partir da vida individual e coletiva.

Justamente por apresentar este caráter subjetivo, o procedimento de validação do processo de pesquisa é um assunto de difícil discussão na área (OLLAIK; ZILLER, 2012). Neste sentido, afirmar que um método ou abordagem é válido carrega uma forte influência positivista oriunda da pesquisa nas ciências naturais, cujo significado é da "extensão em que uma medida representa corretamente o conceito do estudo, ou seja, o grau em que a medida está livre de qualquer erro" (OLLAIK; ZILLER, 2012, p.3). Para pesquisas qualitativas, podemos interpretar que a validade é entendida como o grau de correspondência entre a pesquisa e a realidade (BIANCHI; IKEDA, 2008). Minayo (2008) aponta a triangulação de métodos como forma de aferir validade ao processo de pesquisa qualitativa. Notem, porém, que isto não pressupõe a 


\section{ATOS DE \\ PESQUISA \\ EM EDUCAÇÃO}

ISSN: 1809-0354

utilização obrigatória de métodos quantitativos, mas sim a possibilidade de trabalhar com diferentes metodologias em etapas diferentes do processo de investigação (delineamento, produção ou análise de dados). No presente texto, apresentamos uma discussão referente aos diferentes procedimentos de análise.

Ao considerarmos a linguagem como ferramenta de produção de dados, a análise do discurso produzido pode ser responsável pela descrição dos entrevistados, mais do que um retrato fiel (positivista) de suas afirmações. Afirmamos isso por entender que toda análise textual e/ou discursiva é um processo fortemente ligado ao pesquisador que procede a análise. Dito isso, entendemos que a escolha de metodologia de análise já permite uma inferência sobre a pesquisa em si: seja de forma objetiva, mais ligada à semântica ou aos sinais gráficos, presente na Análise de Conteúdo (BARDIN, 1977); seja de forma subjetiva, ligada à ideologia ou ao próprio sujeito investigado, presente na Análise do Discurso (BAKHTIN, 2012); ou em uma perspectiva intermediária, onde as questões envolvidas e o significado das respostas são envolvidas num processo dialético (MINAYO, 2008).

Devemos ter presente, é claro, que o processo de análise não deve ser considerado como a etapa de um processo racionalista, e por isso assumimos uma postura epistemológica apoiada no anarquismo metodológico (FEYERABEND, 2007). Neste caso, defendemos que um único método de pesquisa, produção e análise de dados não pode ser considerado como o mais correto ou como o único capaz de produzir resultados confiáveis em uma área de pesquisa. Assim, a pesquisa qualitativa, por sua variedade de metodologias de pesquisa, permite uma maior gama de possibilidades quanto ao trabalho investigativo propriamente dito.

Neste sentido, uma proposta metodológica para a análise dos dados produzidos que pode se eximir de pressupostos teóricos a priori vem a agregar mais junto a estas possibilidades de pesquisa. No caso, abordamos a Análise Temática (BRAUN, CLARKE, 2006; ALHOJAILAN, 2012; VAISMORADI et al., 2016), originalmente desenvolvida no contexto da Psicologia e mais comumente utilizada na área da saúde, como forma de tratamento do discurso e do texto na área da Educação, sem a necessidade de embasamento prévio, o que pode inserir um viés no trabalho durante sua execução. 


\section{ATOS DE \\ PESQUISA \\ EM EDUCAÇÃO}

ISSN: 1809-0354

5

Logo, o foco do artigo consiste em investigar a potencialidade analítica deste método aplicado à área da Educação/Ensino de Ciências, considerando seu caráter flexível e sua aparente independência em relação a um referencial teórico definido. Para isso, discutiremos de forma sucinta os aspectos básicos do processo de análise, com especial atenção à Análise Temática. A seguir apresentamos um exemplo, dentro do tópico da formação de professores, investigado pelos autores do texto e apresentamos algumas das conclusões, com as potencialidades da metodologia.

\section{REVISÃO BIBLIOGRÁFICA}

Ao realizarmos uma pesquisa de cunho qualitativo, nossa busca é pela compreensão de problemas enfrentados pelos sujeitos de pesquisa em seu cotidiano, mas que não podem ser simplesmente associados a uma visão positivista de ciência. Ou seja, são necessárias leituras específicas sobre o que é dito, como é dito e o tempo em que é dito. Sem isso, a frieza dos dados tabulados não permite inferir quaisquer relações que se estabeleçam entre os sujeitos de pesquisa, exceto por sua caracterização sócio-histórica.

A partir deste problema, que é a produção dos dados e sua análise, percebemos um espectro de metodologias para trabalhar este discurso falado e escrito, com o intuito de buscar estas aproximações. A literatura (MORAES e GALIAZZI, 2007) costuma colocar nas extremidades deste espectro a Análise de Conteúdo (BARDIN, 1977) e a Análise do Discurso (BAKHTIN, 2012; PECHEUX, 1990; FAIRCLOUGH, 2001) como técnicas diferenciadas que permitem a análise dos dados qualitativos. Entre ambas, podemos localizar proposições analíticas que se aproximam (ou se afastam) de cada uma destas extremidades. Neste meio, podemos inserir a Análise Hermenêutico-Fenomenológica, exemplificada aqui pela Análise Textual Discursiva - ATD (MORAES e GALIAZZI, 2007); a Análise HermenêuticoDialética (MINAYO, 2008) e a Análise Temática (BRAUN e CLARKE, 2006), a qual pretendemos aprofundar neste texto.

A Análise de Conteúdo $(\mathrm{AC})$ tem sua origem no campo das investigações sociais, e busca explicações a partir de uma codificação própria dos dados, a qual permite inferências a partir da maior ocorrência de determinadas palavras (BARDIN, 


\section{ATOS DE \\ PESQUISA \\ EM EDUCAÇÃO}

ISSN: 1809-0354

6

1977). Isso permite que possamos sistematizar tal processo, automatizando este processo de contagem. Seu nascimento remonta à década de 1940, dentro da área jornalística, nos Estados Unidos, mas estendeu-se para uma ampla variedade de setores das ciências humanas, ao longo das décadas seguintes (CAREGNATO e MUTTI, 2006). De forma básica, o texto, na AC, é considerado um meio de expressão dos sujeitos de pesquisa e o analista deve categorizar as unidades de texto de acordo com sua repetição.

Por outro lado, a Análise de Discurso (AD) pode ser elencada em duas linhas clássicas: a francesa (PECHEUX, 1990; FOUCAULT, 2001), que percebe o discurso como uma forma de materialização ideológica, e a americana (FAIRCLOUGH, 2001) que o entende como uma prática social reprodutora e transformadora de realidades sociais, assim também chamada de Análise Crítica do Discurso, uma vez que entende a língua como atividade dialética (MELO, 2009). Para os estudos linguísticos, a AD não é vista como uma metodologia, mas sim como uma disciplina de interpretação, que funde elementos do materialismo histórico, da psicanálise e da linguística (CAREGNATO e MUTTI, 2006). Esta trabalha com o sentido e não com o conteúdo do texto, sentido esse que não pode ser traduzido diretamente, mas produzido ao longo da análise e da leitura.

Uma comparação destas duas formas de análise ( $A C$ e $A D)$ mostra que, em primeiro lugar, a diferença encontra-se na forma como o objeto é acessado pela análise. $\mathrm{Na} \mathrm{AC}$, existem dois tipos de texto acessíveis, os produzidos em pesquisa, como as transcrições de entrevistas, e os já existentes, como artigos e livros. Já na $A D$, temos o corpus do arquivo e o empírico. Ao analisar o material já existente, acessamos o corpus do arquivo; já ao acessarmos o material produzido na pesquisa, este é o corpus empírico, ou experimental. Além disso, a percepção de serem extremos do processo de análise é aumentada pela ideia da $A D$ trabalhar com 0 sentido e a AC com o conteúdo, ou com a materialidade linguística do texto. Qualquer método que utilize estes aspectos de forma mista estará localizado entre os extremos deste espectro.

Neste espaço, encontramos a Análise Hermenêutico-Dialética (AHD). Segundo Minayo (2008), este tipo de análise qualitativa de dados é comumente utilizado em 


\section{ATOS DE \\ PESQUISA \\ EM EDUCAÇÃO}

ISSN: 1809-0354

7

pesquisas na área da saúde. Contudo, Oliveira (2013) apresenta uma metodologia interativa, onde este tipo de análise complementa o Círculo Hermenêutico-Dialético (CHD), proposto por Guba e Lincoln (1989), como estratégia de produção de dados. Sob esta ótica, a AHD é composta por fases comuns à pesquisa qualitativa (MINAYO, 2008) com caracterizações próprias (OLIVEIRA, 2001), a saber:

- a interpretação dos dados, em dois níveis: o das determinações fundamentais, que trata do contexto sócio-histórico dos grupos sob análise e constitui, a priori, o marco teórico da análise; e o de encontro com os fatos empíricos, onde estuda-se a realidade em toda a dinâmica de produção de dados;

- a ordenação dos dados, onde eles são sistematizados de forma a facilitar o processo de reconhecimento seguinte;

- a classificação dos dados, onde eles são percebidos a partir dos questionamentos feitos sobre eles, com base nos fundamentos teóricos, e onde os dados são identificados como relevantes para a explicação destes questionamentos, podendo ser agrupados em categorias ao longo do processo; e

- a análise final, onde estes dados são articulados com os referenciais teóricos, de maneira a proporcionar respostas aos questionamentos de pesquisa, seguindo (ou não) os objetivos delineados no projeto da pesquisa.

Sob o ponto de vista metodológico, podemos enxergar a hermenêutica como uma busca de diferença e/ou semelhanças entre contextos próprios dos sujeitos da pesquisa e do investigador, assim como de um compartilhamento entre as percepções de mundo dos sujeitos com o investigador. Articulada à dialética, onde o diálogo e a controvérsia estão presentes, temos uma forma de valorizar complementaridades e divergências próprias das situações em análise. Esse procedimento pode ser ilustrado na Figura 1, onde as etapas da AHD são mostradas sob a forma de fluxograma. 


\section{ATOS DE \\ PESQUISA \\ EM EDUCAÇÃO}

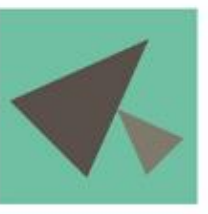

ISSN: 1809-0354

Figura 1 - Fluxograma da Análise Hermenêutico-Dialética

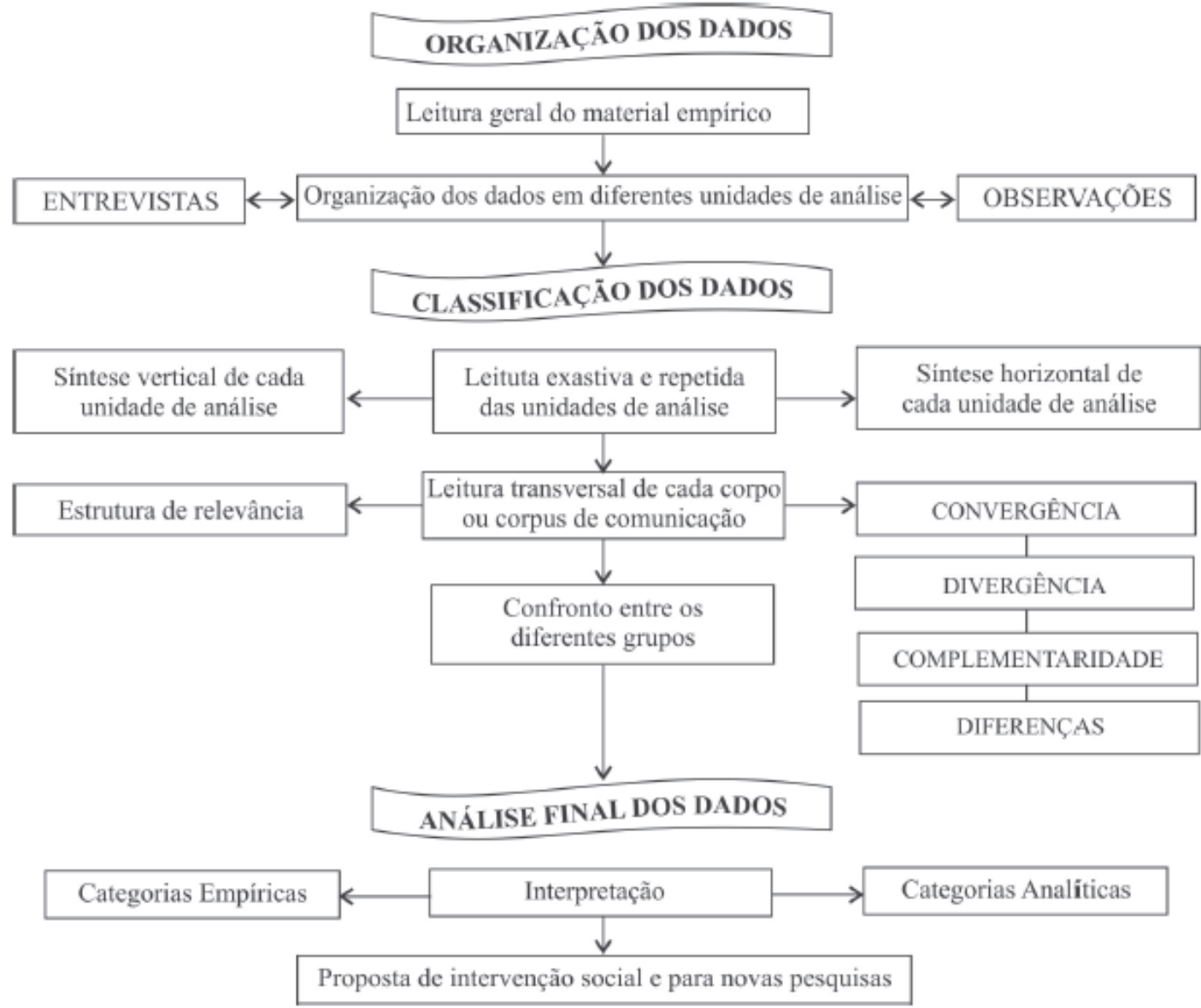

Fonte: Assis e Jorge (2010).

Podemos notar neste fluxograma a percepção clara que sentido e conteúdo têm papéis complementares ao longo da análise. Além disso, o procedimento analítico pressupõe um embasamento teórico definido, uma vez que as produções de sentido na organização dos dados produzidos precisam estar ligadas ao referencial teórico (MINAYO, 2008).

De outra forma, a Análise Hermenêutico-Fenomenológica (AHF) se caracteriza pela participação, ativa e reflexiva, do pesquisador, de maneira a este não se permitir a impessoalidade e neutralidade na pesquisa. Assim, segundo Freire (2012), as possíveis interpretações e construções de significado são consideradas de acordo com as histórias de vida do próprio pesquisador. Neste processo, identificamos (AZEVEDO, 2016): 


\section{ATOS DE \\ PESQUISA \\ EM EDUCAÇÃO}

ISSN: 1809-0354

- a tematização, como é chamada a interpretação do fenômeno, a partir de leituras e releituras dos textos coletados, a partir da identificação de temas que caracterizam constituição e essência do fenômeno em estudo;

- o refinamento e a ressignificação, onde as unidades de significado associadas aos temas elencados são identificadas e avaliadas quanto a sua relevância no processo, de maneira a captar a essência do fenômeno;

- a narrativa, que fecha os temas elencados de maneira unificada, uma vez que seguem um intenso mergulhar no conjunto de dados, novamente associada ao referencial teórico.

Notem que este trabalho pode ser percebido, igualmente, quando nos referimos a Análise Textual Discursiva - ATD (MORAES; GALIAZZI, 2007), passando por redefinições da nomenclatura das etapas, onde temos a unitarização, que é o processo de fragmentação e codificação do texto, com a criação das unidades de significado (US); a categorização, onde estas US são reunidas em grupos que vão "emergindo"1 com novos sentidos e significados, "inicialmente imprecisas e inseguras, mas gradativamente sendo explicitadas com rigor e clareza" (MORAES; GALIAZZI, 2006 , p. 125); e finalmente, estas categorias geram metatextos, onde o referencial teórico é revisitado, gerando uma interlocução entre as categorias elencadas pelos dados e estes autores, que embasam a discussão e o movimento do pesquisador.

Portanto, ao escolhermos uma técnica específica de análise para os dados que produzimos, carregamos conosco um arcabouço teórico que, sob certo aspecto, nos limita e nos direciona neste procedimento analítico. Mais ainda, em muitos casos, este referencial dirige também o processo de pesquisa desde a produção destes dados, como o apontado, por exemplo, por Oliveira (2013), onde a metodologia de pesquisa e o procedimento analítico são complementares.

Para evitar estas amarras teóricas, apresentamos na próxima seção a proposta da Análise Temática, vista por Minayo (2008) como uma etapa do procedimento analítico, mas definida na área da saúde e na Psicologia, por Braun e Clarke (2006) como uma postura analítica não definida pelo referencial teórico, mas sim associada

\footnotetext{
${ }^{1}$ Utilizamos a expressão entre aspas por entender que a ideia de emergência, ao ser utilizada no contexto de análise textual, está associada a algo inesperado, que realmente surja dos dados surpreendendo o pesquisador, ao invés de algo que está bem definida como resposta à questão de pesquisa.
} 


\section{ATOS DE \\ PESQUISA \\ EM EDUCAÇÃO}

ISSN: 1809-0354

10

diretamente ao texto (escrito ou falado), podendo ser definidos os temas ligados a literatura analisada ou então pré-definidos pelo pesquisador.

Aqui, já apontamos a principal razão para apresentar a AT, que é o fato de podermos fazer uma análise geral, muito semelhante à hermenêutica, e poder utilizar os códigos gerados para fazer comparações em diversos referenciais teóricos. Isso não pode ser feito na Análise do Discurso, ou nas análises hermenêuticas (dialética ou fenomenológica), pois ambas estão associadas a arcabouços teóricos definidos.

\section{A ANÁLISE TEMÁTICA}

A análise temática é apontada como um método analítico pouco demarcado e reconhecido, mas amplamente utilizado na área da Psicologia (BRAUN e CLARKE, 2006). Segundo as autoras, este tipo de análise ainda é considerado como um método muito mal delimitado, justamente por aparentar não existir como uma análise nomeada como identificamos em outros métodos. Ainda que não seja explicitamente reivindicada como um método de análise, argumentamos que boa parte da análise se apresenta como temática, podendo ser reivindicada como outra coisa ou não adotada como um método específico.

Na verdade, um dos benefícios da Análise Temática (AT) é a sua flexibilização, para Braun e Clarke (2006, p. 3) "através da sua liberdade teórica, a análise temática fornece uma ferramenta de pesquisa flexível e útil, que pode potencialmente fornecer um conjunto rico e detalhado, ainda que complexo de dados".

Nesse sentido, Braun e Clarke (2006) apontam que a AT consiste no primeiro método qualitativo de análise que os pesquisadores precisam aprender, pois contém habilidades centrais que são essenciais para a realização de muitas outras formas de análise qualitativa. As pesquisadoras destacam que uma análise temática devidamente nomeada e reconhecida não exige que os pesquisadores tenham que subscrever os compromissos teóricos implícitos da teoria fundamentada, se o objetivo não for uma análise totalmente trabalhada na questão da fundamentação.

Cabe ressaltar que a análise temática pode se apresentar como um 


\section{ATOS DE

método essencialista ou realista, que relata experiências, significados e a realidade dos participantes, ou pode ser um método construtivista, que examina as maneiras como eventos, realidades, significados, experiências e assim por diante são feitos de uma série de discursos que operam dentro da sociedade. Também pode ser um método 'contextualista', localizado entre os dois polos do essencialismo e construtivismo (...). Portanto, a análise temática pode ser um método que funciona tanto para refletir a realidade, como para desfazer ou desvendar a superfície da 'realidade'. No entanto, é importante que a posição teórica de uma análise temática seja clara, já que esta é muitas vezes não mencionada (e é, então, normalmente, de caráter realista) (BRAUN; CLARKE, 2006, p. 7-8, tradução nossa).

Além disso, na análise temática, os temas ou padrões dentro dos dados podem ser identificados por indução ou por dedução. A análise indutiva é guiada pelos dados, sem tentar se encaixar em um modelo de codificação preexistente ou preconceitos analíticos do pesquisador. Todavia, como uma análise teórica ou dedutiva é, consequentemente, mais explicitamente orientada pelo analista, esta forma de análise tende a descrever menos os dados em geral, ressaltando de forma mais detalhada apenas alguns aspectos dos dados (BRAUN; CLARKE, 2006).

Contudo, a análise temática nos dá a possibilidade de fornecer uma descrição mais detalhada e diferenciada sobre um determinado tema específico ou grupo de temas, dentro da análise de dados. Atrelado a isso, é importante decidir em que nível os temas deverão ser identificados. Vale lembrar que estes podem ser identificados pelo nível semântico ou latente. A esse respeito, as pesquisadoras destacam que:

Com uma abordagem semântica, os temas são identificados dentro dos significados explícitos ou superficiais dos dados, e o analista não está à procura de qualquer coisa além do que um participante tenha explicitado ou dito ou escrito. (...)

Em contraste, uma análise temática a nível latente vai além do conteúdo semântico dos dados, e começa a identificar ou examinar as ideias, suposições e conceitualizações - e ideologias - subjacentes que são teorizados como formação ou informação do conteúdo semântico dos dados (BRAUN; CLARKE, 2006, p, 11, tradução nossa).

Portanto, a análise temática envolve a busca a partir de um conjunto de dados, seja originário de entrevistas, grupos focais ou de uma série de textos, a fim de encontrar os padrões repetidos de significado. Braun e Clarke (2006) descrevem que a análise envolve um constante movimento para frente e para trás pelo conjunto de dados, ou seja, pelo o que se está analisando dos extratos codificados ou já produzindo a partir da análise. Assim, a escrita surge como uma parte integral da 


\section{ATOS DE \\ PESQUISA \\ EM EDUCAÇÃO}

ISSN: 1809-0354

análise, não como algo deixado apenas para fim, como ocorre com as análises estatísticas.

As autoras apresentam seis fases para a realização da análise temática, e apontam algumas contribuições acerca de cada fase envolvida que serão brevemente descritas:

Fase 1: Familiarização com os dados - É fundamental que o pesquisador mergulhe nos dados, ao ponto de alcançar com profundidade e amplitude o conteúdo. A imersão geralmente envolve a leitura repetida dos dados, que leva a uma procura por significados, padrões e assim por diante. É um exercício de leitura e releitura dos dados, portanto, é um processo demorado, pois fornece a base para o resto da análise;

Fase 2: Geração dos códigos iniciais - Envolve a produção de códigos iniciais a partir dos dados. É por meio dos códigos que o pesquisador identifica as características dos dados (conteúdo semântico ou latente) que pode ser considerada em relação ao fenômeno. Todavia, os dados codificados diferem-se das unidades de análise que representam os temas e que são muitas vezes mais amplos;

Fase 3: Busca por temas - Esta fase só se inicia quando todos os dados forem inicialmente codificados e agrupados e já se tem uma longa lista de códigos diferentes que foram previamente identificados no conjunto de dados. Portanto, esta fase envolve a triagem dos diferentes códigos em temas potenciais, sendo que alguns códigos iniciais podem passar a formar temas principais, outros podem virar subtemas, enquanto outros podem ser descartados;

Fase 4: Revisão dos temas - É uma fase que envolve dois níveis: o primeiro consiste na revisão dos extratos codificados nos dados, o segundo envolve 0 refinamento desses temas. Enfim, nesta fase é importante reler o conjunto de dados e verificar se os temas trabalham bem com relação ao conjunto de dados ou é necessário codificar quaisquer dados adicionais dentro dos temas, que por ventura tenham sido perdidos em estágios anteriores da codificação;

Fase 5: Definição e denominação dos temas - Surge quando já se tem um mapa temático satisfatório dos dados e passa para os refinamentos finais, ou seja, pode- se refinar ainda mais os temas que serão apresentados ao final da análise. É 


\section{ATOS DE \\ PESQUISA \\ EM EDUCAÇÃO}

ISSN: 1809-0354

fundamental que, ao final desta fase, tenha-se a clareza o que os temas são e o que eles não são. Além disso, é nesta fase que se dará o título de trabalho aos temas, portanto, os nomes precisam ser concisos, diretos, ao ponto de o leitor ter uma ideia clara sobre o tema;

Fase 6: Produção do relatório - Esta fase começa quando se tem o conjunto de dados totalmente trabalhados, e contempla a análise final e a escrita do relatório. Assim, é importante que a análise escrita forneça um relatório conciso, coerente, lógico, que contenha provas suficientes dos temas nos dados, enfim, que escolha exemplos vividos, ou extratos que capturem a essência do ponto que será demonstrado.

Em suma, algumas das fases da AT são semelhantes às fases de outras pesquisas qualitativas não sendo, portanto, etapas necessariamente exclusivas a este tipo de análise. Portanto, "a análise temática é uma abordagem flexível que pode ser usada por uma variedade de epistemologias e questões de pesquisa" (BRAUN; CLARKE, 2006, p, 28, tradução nossa).

Do ponto de vista da pesquisa qualitativa, é importante que reconheçamos nossas próprias posições e valores teóricos, pois nem sempre "pensamos que existe um quadro teórico ideal para a realização da pesquisa qualitativa, ou mesmo um método ideal" (BRAUN; CLARKE, 2006, p. 6, tradução nossa). É fundamental que o padrão teórico e os métodos correspondam ao que o pesquisador de fato quer saber, e os reconheçam como decisões.

Para fins de comparação, a análise de conteúdo pode ser contemplada como uma análise dos significados, como é o caso da análise temática, embora possa ser também uma análise dos significantes. Bardin (1977) atribui que a análise tem como procedimento inicial o tratamento descritivo, que também compete a outras formas de análise como a linguística e as técnicas documentais.

Nesse sentido, Bardin (1977) destaca que a preocupação da linguística é o estudo da língua, e a análise então se utiliza deste mecanismo para buscar outras realidades através das mensagens, ou seja, seus significados. Com relação às técnicas documentais o objetivo da análise é a manipulação das mensagens, que está atenta ao conteúdo e a expressão desse conteúdo. 


\section{ATOS DE \\ PESQUISA \\ EM EDUCAÇÃO}

ISSN: 1809-0354

14

Para ilustrar o processo de análise temática, na próxima seção nos debruçamos sobre uma situação de pesquisa, onde investigamos a percepção da inovação pedagógica a partir da formação dos professores em nível de pós-graduação stricto sensu. Para este propósito, foram coletadas respostas a um questionário escrito, referentes a 16 professores ${ }^{2}$ da disciplina de Ciências nas Séries Finais do Ensino Fundamental na cidade de Rio Grande/RS. A opção pela aplicação de questionários, e não de entrevistas, foi uma escolha onde se ponderou também o tempo disponível para os professores, que é escasso em função do número de horas de aula que precisam cumprir em uma (ou várias) escola(s). Atrelado a este fator, outro aspecto observado, foi o fato de que não é comum, no espaço escolar, a disponibilização de espaços reservados para o professor, o que dificultaria a dinâmica por entrevistas, uma vez que os espaços que se têm são aqueles utilizados de forma coletiva (ROSA, 2019).

\section{RESULTADOS E DISCUSSÃO}

Ao coletar os dados dos professores envolvidos foi possível percorrer as seis fases da Análise Temática e obter a definição e a denominação dos temas. Os dados coletados nos questionários foram digitados de forma sequencial, de maneira a comparar todas as respostas dos participantes para cada questionamento apresentado, o que permitia maior familiarização com os dados e facilitava a geração inicial de códigos, onde surgiam termos específicos em destaque, mas ainda sem a pretensão de definir categorias ou temas a serem analisados.

Na primeira etapa, da familiarização com os dados, nossa operação foi de uma leitura exploratória, buscando captar as informações apresentadas nos textos coletados, bem como fazendo uma identificação prévia de temas que se destacavam e/ou repetiam ao longo de nossa leitura. Nesta etapa, as respostas dos professores entrevistados são analisadas e são marcados temas possíveis que se enquadrem naqueles definidos anteriormente. Nessa etapa, é importante que o processo se dê em um único movimento, sob o risco de não se perceber tais temas prévios nesta

\footnotetext{
2 Para efeitos de ilustração, serão definidos por Pn, com n entre 1 e 16.
} 


\section{ATOS DE

etapa, o que aumenta o trabalho nas etapas seguintes. Esta contagem de ocorrências, apesar de não ser obrigatória para a AT, a aproxima da metodologia de codificação da AC. Ainda podemos assumir livremente que tenhamos temas definidos a priori, que são definidos já na leitura do referencial para produção dos dados. No nosso caso, estes temas iniciais são inovação pedagógica e cultura docente. De nossa primeira leitura, já percebemos que este segundo tema seria amplo e precisaria ser rediscutido, de onde surgem novos temas: realidade escolar e desafios docentes. Isso mostra que, apesar de uma intenção de pesquisa em relação a pontos definidos anteriormente, esta etapa nos permite já criticar a abrangência destes pontos prévios.

$\mathrm{Na}$ segunda etapa, de posse de marcadores de texto (sejam físicos para o texto impresso, sejam cores diferentes na cópia digital), selecionamos aspectos identificados aos temas que se destacaram na primeira etapa. Ou seja, agora começamos o processo de análise comparativa, identificando os elementos das falas dos entrevistados aos temas previamente estabelecidos. Mesmo assim, este procedimento ainda se identifica como uma identificação, com a geração de códigos associados aos temas, ainda sem a preocupação de que estes estejam presentes na estrutura final. Como apontamos antes, os códigos identificam tanto o significado semântico quanto o latente, fazendo a ponte entre a $A C$ e a $A D$, o que reforça a percepção de que a AT não está ligada a um referencial teórico específico. Importante destacar que novos temas surgem a cada momento, e nesta etapa podem ocorrer confusões sobre onde enquadrar determinados códigos produzidos nas entrevistas. Isso reforçou, em nosso caso, a necessidade de se desprender do tema cultura docente, uma vez que ele se tornou pouco capaz de discriminar aspectos entre os códigos identificados. Por exemplo, elementos que estavam associados à realidade enfrentada pelos professores se distanciavam daqueles que traziam os desafios apresentados no exercício da docência, fazendo com que a temática inicial abrangesse um grande número de códigos distintos.

$\mathrm{Na}$ terceira etapa, entre estes códigos iniciais, uma leitura crítica, aprofundada, traz as primeiras sugestões de temas. Inicialmente aparecendo apenas como destaques ao texto codificado, confrontamos tais temas com nosso referencial teórico, percebendo neste processo que um deles estava pré-definido em nossa questão de 


\section{ATOS DE \\ PESQUISA \\ EM EDUCAÇÃO}

ISSN: 1809-0354

16

pesquisa. Conforme já discutimos, isso não invalida o procedimento analítico na AT, uma vez que esta não precisa estar fundamentada na teoria, mas o fato de revisitar o embasamento teórico implica em reforçar os temas gerados.

Conforme apontam Braun e Clarke (2006), estes temas precisam ser testados, revisados para verificar se representam a amostra de dados qualitativos que temos. Nesta quarta etapa, já conseguimos perceber se os temas "funcionam" ou não quanto ao seu poder descritivo sobre a amostra. Por exemplo, aqui podemos verificar se os temas estão de acordo com a questão de pesquisa e, por isso, têm força para respondê-la. No nosso caso, um deles pode ser considerado como previamente definido (relacionado à própria ideia de inovação pedagógica) e os outros dois surgiram dos discursos percebidos (a possibilidade de ascensão e os desafios da docência). Ou seja, os códigos gerados ao longo das etapas iniciais puderam ser agrupados de acordo com estes temas. Em nossa análise, como utilizamos o texto, escolhemos não criar tabelas ou nuvens de palavras, mas sim ir destacando os códigos com marcadores de três cores diferentes, sinalizando cada tema.

A partir disso, a quinta e sexta etapa são praticamente simultâneas, uma vez que a denominação final dos temas está muito ligada à elaboração do relatório. Este revisita os aspectos teóricos relacionados ao trabalho de pesquisa, agora apresentando os temas que surgiram no procedimento analítico. Neste processo, foram identificados três temas: Formação Continuada como Possibilidade de Inovação Pedagógica; Formação Continuada como Ascensão Pessoal e Profissional; e Desafios da Docência.

Considerando o caráter didático deste trabalho, apresentamos como exemplo de relatório somente o terceiro tema, denominado "Os desafios da docência", onde buscamos compreender as dificuldades que os professores de Ciências enfrentam para conciliar sua jornada de trabalho juntamente com a Formação Continuada. Notem que este tema dialoga com uma bibliografia específica, associada à formação de professores e à atuação docente, por isso não relacionada ao referencial do presente artigo. 


\section{ATOS DE \\ PESQUISA \\ EM EDUCAÇÃO}

ISSN: 1809-0354

\subsection{Tema: os desafios da docência}

O Ensino de Ciências exige do professor uma contínua formação, que se justifica diante do rápido avanço científico e tecnológico e das constantes mudanças de cunho social, político, cultural e pedagógico. Pensar no papel que o educador exerce, nos dias atuais, não é uma tarefa fácil, a começar pele organização de trabalho, que os padroniza seguir uma lógica padrão.

Os professores passam a desempenhar muitas responsabilidades, tais como: preparação das aulas, correções das atividades avaliadas, preenchimento de cadernos de chamada, entrega de notas, participação em conselhos de classe. Muitos ainda precisam conciliar uma dupla ou até mesmo tripla jornada de trabalho, levandoos a exercer suas atividades profissionais, por vezes, em mais de um estabelecimento escolar.

Atrelado a esta situação, muitos convivem com a falta de recursos materiais e de espaço físico para desenvolver suas atividades e a maior parte das escolas se quer oferecem aos professores a possibilidade de dialogar e partilhar experiências. Neste cenário, destacam-se também as dificuldades impostas pelo currículo, as condições salariais baixas, o elevado número de alunos por turma, a distorção por série-idade e a inclusão de alunos com deficiência, aspecto visto por muitos docentes como um desafio devido à falta de preparação para lidar com as peculiaridades de cada ser.

Diante desta perspectiva, os professores de Ciências veem a formação como necessária para o aperfeiçoamento profissional, em vista das dificuldades que 0 ensino exige. A pesquisa destaca que os educadores se sentem atraídos a buscar os programas de Pós-Graduação, contudo, muitos acabam desistindo, por não conseguir cumprir as exigências do trabalho juntamente com as da formação.

Para Nóvoa (2017), os professores têm passado por uma desprofissionalização que "manifesta-se de maneiras muito distintas, incluindo níveis salariais baixos e difíceis condições nas escolas, bem como processos de intensificação do trabalho docente por via de lógicas de burocratização e de controlo" (p. 1109).

A rigorosidade em ter que conciliar a profissão, foi um dos principais aspectos identificados pela análise que levaram os professores a desistir dos cursos de PósGraduação. Fator este que é reconhecido nos trechos a seguir: 


\section{ATOS DE

“[...] o Ensino de Ciências não é algo estático e necessitamos estar sempre buscando novas leituras e conhecimentos. Sinto ter que possuir uma carga horária de trabalho tão elevada que acaba me impossibilitando de buscar o Doutorado" (P4).

"Iniciei a formação assim que concluí a graduação. Quando iniciei a trabalhar na rede municipal acabei desistindo, pois não consegui conciliar estudo e 50 horas de trabalho" (P7).

"[...] até começar a trabalhar foi bom, depois perto de abandonar o PPG, tive início de depressão pelas cobranças de não dar conta" (P8).

"[...] justamente por ser chamada no concurso do estado e nomeada para o interior de São José do Norte em Bujuru, que tive que parar o mestrado, pois já estava na parte onde não conseguia conciliar os dois devido a distância, pois vinha à Rio Grande de 15 em 15 dias" (P10).

Sem dúvida, é evidente que o excesso de cobranças que os professores sentem vem a ser um dos maiores desafios que impedem que mais professores busquem este tipo de qualificação. Quanto a isto, é importante ressaltar que não há por parte da Secretária Municipal de Educação uma política que garanta o acesso dos professores aos programas de Pós-Graduação, disponibilizando uma redução de carga horária para que os mesmos possam realizar a qualificação. Apesar de existir mecanismos previstos por lei, ainda é muito difícil existir esta liberação para capacitação dos professores, ainda mais quando esta exige um afastamento maior do professor da convivência escolar, passando a conviver com o meio acadêmico e assim modificar suas práticas.

A única conquista que se tem quanto à formação, é a possibilidade da projeção de nível ao Plano Municipal de Carreira, para aqueles professores que conquistaram por mérito seu, a qualificação em cursos de Mestrado ou Doutorado. Logo, é preciso que haja investimentos, no sentido de ofertar, as condições para que mais professores consigam prosseguir.

Contudo outra realidade comtemplada pelos professores indicou que grande parte dos programas de Pós-Graduação não são opções acessíveis para profissionais da educação.

“[...] a experiência que tive me mostrou que PPG's são inacessíveis para trabalhadores em educação uma vez que a jornada de trabalho não se limita a sala de aula. A modalidade a distância se adequa mais as possibilidades" (P8).

Ao analisarmos historicamente a criação dos cursos de Pós-Graduação Stricto Sensu em nosso país, percebemos que o emprego da modalidade acadêmica, é direcionada a formação de pesquisadores, característica esta, que condiz e favorece 


\section{ATOS DE \\ PESQUISA \\ EM EDUCAÇÃO}

ISSN: 1809-0354

19

o preenchimento das vagas, com o perfil de estudantes acadêmicos vindos da Graduação. Já a modalidade profissional, passa a ser uma melhor opção para os professores que trabalham, de acordo com o professor P12:

\footnotetext{
"Pena que o empregador não dê o devido valor; e que a maioria dos programas de pósgraduação sejam tão fechados e intolerantes ao "novo". Gostei muito do MNPEF, justamente pela versatilidade e flexibilidade a que foi proposto" (P12).
}

Segundo a LDB as instituições formativas deverão manter programas de formação continuada para os profissionais de educação dos diversos níveis, assim como os sistemas de ensino, que deverão promover aperfeiçoamento profissional continuado (BRASIL,1996).

Logo, é preciso que as instituições formadoras, invistam na criação de cursos e linhas de pesquisa que atendam os professores da rede básica de ensino. Inclusive, a acessibilidade dos professores aos programas, é uma das metas a serem alcançados pelo Plano Nacional de Educação - PNE que pretende "Formar em pósgraduação pelo menos 50\% de professores da Educação Básica" (CAPES, 2017, p. 08).

Teoricamente falando as inciativas são válidas, contudo, é preciso assegurar as condições de trabalho para que os professores se sintam motivados a buscar os programas de Pós-Graduação. No entanto, o que garante a permanência dos professores junto aos programas, é o sentido de pertencimento, o docente precisa sentir que faz parte do processo, assumir-se como pesquisador da sua área.

Enfim, muitos destes argumentos mencionados, de fato pesaram para que parte dos professores pesquisados não concretizasse a Pós-Graduação. Os dados da análise mostraram que dos 16 professores que passaram pela Formação Continuada, 6 não conseguiram concluir.

Esta dura constatação nos faz pensar o quanto temos que investir em políticas públicas e investimentos nesta área. Logo, é preciso que as Universidades, assim como a Secretária de Educação e as Instituições de Ensino, unam-se no sentido de traçar esforços para que mais professores tenham acesso e o direito assegurado de terminar sua qualificação junto aos programas de Pós-Graduação Stricto Sensu. 


\section{ATOS DE \\ PESQUISA \\ EM EDUCAÇÃO}

ISSN: 1809-0354

Precisamos repensar como nos diz Nóvoa (2017) com coragem e ousadia, as nossas instituições e as nossas práticas de ensino. Se não o realizarmos, "estaremos a reforçar, nem que seja por inércia, tendências nefastas de desregulação e privatização. A formação de professores é um problema político, e não apenas técnico ou institucional" (p. 1111).

Como últimas palavras nesta seção, podemos relembrar que a própria percepção dos professores analisados é de mudança em sua prática, mesmo que a ênfase de sua Pós-Graduação seja mais técnica. Isso nos motiva a entender a perspectiva inovadora que a Formação Continuada traz para a prática docente, mesmo quando não questiona aspectos relacionados diretamente a esta prática.

\section{CONCLUSÕES}

Para encerrarmos este trabalho, onde apresentamos uma comparação entre metodologias de análise de dados qualitativos, com especial atenção à Análise Temática, gostaríamos de apontar que, conforme apontam Minayo (2008) e Appolinario (2006), existe um padrão para procedimento analítico para dados qualitativos, com etapas nomeadas diferentemente nas diferentes metodologias de análise. Este padrão segue a linha: leitura atenta - criação de unidades categorização - relatório final. Aqui, não questionamos ou apontamos nomes diferentes para cada etapa, mas destacamos o desprendimento inicial em relação ao embasamento teórico, o que torna a AT uma forma mais flexível de análise qualitativa.

Esta, aliás, é a principal motivação para a escrita deste trabalho. Ao longo do trabalho de pesquisa para a tese de doutoramento de um dos autores, 0 questionamento que nos assombrava era a imposição teórica de uma metodologia de análise, o que introduzia um viés no procedimento analítico, no nosso ponto de vista. Ao escolher a AT como metodologia de análise, esta preocupação de dialogar com os teóricos é postergada para a fase da elaboração dos relatórios, o que dá maior liberdade para a análise e determinação dos temas que respondem a questão de pesquisa. Chamamos atenção que esta escolha foi motivada pela liberdade de referenciais, e defendemos sua consideração como metodologia de análise por tal 


\section{ATOS DE \\ PESQUISA \\ EM EDUCAÇÃO}

ISSN: 1809-0354

21

motivo. Não buscamos comparar com outras metodologias de análise qualitativas, uma vez que a utilização de cada uma está ligada à apropriação teórica de seus embasamentos, e isto faz parte dos procedimentos de pesquisa. No entanto, ao pensar numa forma de apresentar metodologias de análise, ou nos casos onde a pesquisa é realizada a partir de uma questão definida, não associada a uma linha teórica clara.

Assim, ao exemplificarmos a operação da Análise Temática a partir da pesquisa por nós desenvolvida, buscamos apresentar a metodologia para sua utilização nas áreas de Educação e Ensino, uma vez que a mesma tem sido utilizada de forma sistemática na Psicologia (BRAUN e CLARKE, 2006) e na Enfermagem (VAISMORADI et al., 2016), bem como em outros trabalhos da área da saúde. Entendemos que, assim, propomos a utilização de um procedimento analítico que propicia maior liberdade ao analista, o que permite sua aplicação a diferentes vertentes teóricas e metodológicas.

\section{LIANE SERRA DA ROSA}

Licenciada em Ciências Biológicas (UCPel/2005), Mestre (2015) e Doutora (2019) em Educação em Ciências, pela Universidade Federal do Rio Grande - FURG. Atua como professora de Ciências nas Séries Finais do Ensino Fundamental no Centro de Atenção Integral à Criança e ao Adolescente - CAIC/FURG. Atua especialmente na pesquisa nas áreas de formação de professores e inovações pedagógicas.

\section{LUIZ FERNANDO MACKEDANZ}

Licenciado em Física (UFPel/2000), Mestre em Física (UFRGS/2003) e Doutor em Ciências (UFRGS/2008), é Professor Associado do Instituto de Matemática, Estatística e Física (IMEF) da Universidade Federal do Rio Grande - FURG. Atua no Programa de Pós-Graduação em Educação em Ciências, com trabalhos relacionados às inovações pedagógicas no Ensino de Ciências, formação e professores e estratégias de mensuração de níveis de alfabetização científica.

\section{REFERÊNCIAS}

ALHOJAILAN, M. I. Thematic Analysis: a critical review of its process and evaluation. West East Journal of Social Sciences, v. 1, n. 1, p. 39-47, 2012.

APPOLINARIO, F. Metodologia da Ciência: filosofia e prática da pesquisa. São Paulo: Thompson, 2006. 


\section{ATOS DE \\ PESQUISA \\ EM EDUCAÇÃO}

ISSN: 1809-0354

22

AZEVEDO, A. B. Meios digitais em práticas pedagógicas na educação: uma análise hermenêutica-fenomenológica. Santa Maria, v. 41, n. 2, p. 491-504, 2016.

BAKHTIN, M. Marxismo e filosofia da linguagem: problemas fundamentais do método sociológico na Ciência da Linguagem. 13 ed. São Paulo: Hucitec, 2012.

BARDIN, L. Análise de conteúdo. Lisboa: Edições 70, 1977.

BIANCHI, E. M. P. G.; IKEDA, A. A. Usos e aplicações da grounded theory em Administração. GESTÃO.Org, v. 6, n. 2, p. 231-248, 2008.

BOYATZIS, R. E. Transforming qualitative information: Thematic analysis and code development. Thousand Oaks, CA: Sage. 1998.

BRASIL. Lei no 9.394 de 1996. Estabelece as diretrizes e bases da educação nacional. Brasília, 1996. Disponível em <http://www.planalto.gov.br/ccivil_03/Leis/ L9394.htm>. Acesso em: 03 out. 2018.

BRAUN, V.; CLARKE, V. Using thematic analysis in psychology. Qualitative Research in Psychology, v. 3, n. 2. p. 77-101. 2006.

CAPES. Ministério da Educação. Coordenação de Aperfeiçoamento de Pessoal de Nível Superior. Diretoria de Avaliação. Relatório de Avaliação - Ensino: 2013-2016 Quadrienal. 2017. Disponível em: < https://capes.gov.br/images/stories/download/ avaliacao/relatorios-finais-quadrienal-2017/20122017-ENSINO-quadrienal.pdf>. Acesso em: 22 mar. 2019.

CAREGNATO, R. C. A., MUTTI, R. Pesquisa qualitativa: análise de discurso versus análise de conteúdo. Texto Contexto Enfermagem, Florianópolis, v. 15, n. 4, p. 679684, 2006.

FAIRCLOUGH, N. Discurso e Mudança Social. Brasília: UNB, 2001.

FOUCAULT, M. A ordem do discurso. 7ª̣ ed. São Paulo: Edições Loyola, 2001.

FEYERABEND, P. Contra o método. São Paulo: Ed. UNESP, 2007.

FREIRE, M. M. Da aparência à essência: a abordagem hermenêuticofenomenológica como orientação qualitativa de pesquisa. In: ROJAS, J.;

STREINGHETA, L. M. (Orgs.). Educação, pesquisa e prática docente em diferentes contextos. 1. ed. São Paulo: Life Editora, 2012.

GUBA, E.S., LINCOLN, Y. S. Fourth generation evaluation. Newsbury Park: Sage, 1989. 


\section{ATOS DE \\ PESQUISA \\ EM EDUCAÇÃO}

ISSN: 1809-0354

23

MELO, I. F. Análise do Discurso e Análise Crítica do Discurso: desdobramentos e intersecções. Letra Magna - Revista Eletrônica de Divulgação Científica em Língua Portuguesa, Linguística e Literatura, v. 5, n. 11, 2009. 18 pp.

MINAYO, M. C. S. O desafio do conhecimento: pesquisa qualitativa em saúde. São Paulo: Hucitec, 2008.

MORAES, R, GALIAZZI, M. C. Análise Textual Discursiva: processo reconstrutivo de múltiplas faces. Ciência \& Educação, v. 12, n. 1, p. 117-128, 2006.

MORAES, R., GALIAZZI. Análise Textual Discursiva. ljuí: Ed. Unijuí, 2007.

NÓVOA, A. Firmar a posição como professor, afirmar a profissão docente. Cadernos de Pesquisa, v. 47, n. 166, p. 1106-1133, 2017.

OLIVEIRA, M. M. Metodologia Interativa: um processo hermenêutico dialético. Interfaces Brasil/Canadá, Porto Alegre, v. 1, n. 1, p. 67-78, 2001.

OLIVEIRA, M. M. Sequência Didática Interativa no processo de formação de professores. Petrópolis: Ed. Vozes. 2013.

OLLAIK, L. G.; ZILLER, H. M. Concepções de validade em pesquisas qualitativas. Educação e Pesquisa, São Paulo, v. 38, n. 1, p. 229-241, 2012.

PÊCHEUX, M. Análise automática do discurso. In: GADET, F. HAK, T. (Orgs.). Por uma análise automática do discurso - introdução à obra de Michel Pêcheux. Campinas: Unicamp. pp $61-161,1990$.

ROSA, L. S. A formação continuada como estratégia de inovação pedagógica: uma análise sobre a concepção dos professores de Ciências. Tese de doutorado Programa de Pós-Graduação em Educação em Ciências. Rio Grande: Universidade Federal do Rio Grande: PPGEC, 2019. 106 pp. Disponível em $<$ https://ppgec.furg.br/teses/14-teses $>$.

STAKE, R. E. Pesquisa qualitativa/naturalista: problemas epistemológicos. Educação \& Seleção, v. 7, p. 19-27, 1983.

VAISMORADI, M., JONES, J., TURUNEN, H., SNELGROVE, S. Theme development in qualitative content analysis and thematic analysis. Journal of Nursing Education and Practice, v. 6, n. 5, p. 100-110, 2016.

Recebido em: 04/10/2019.

Aprovado em: 28/05/2020. 